\title{
An Assessment of Cost of Access to Health Services of Severely Disabled People in Chitwan
}

\author{
Chudamani Poudel ${ }^{1}$ and Ramesh Baral ${ }^{2}$ \\ 1. People with Spinal Cord Injury National Network Nepal \\ 2. PHD Scholar, Tribhuvan University \\ Correspondence: Chudamani Poudel (kundanyaatra@gmail.com)
}

\begin{abstract}
There are many barriers that keep people with disabilities from fully engaging in health care services. This study assessed the direct medical, direct non-medical and indirect cost as well as potential barriers and obstacles that people with spinal cord injury and intellectual disabilities faced in accessing health care services. This study conducted in Chitwan district of Nepal used both quantitative and qualitative information. For quantitative study, structured interview were conducted to assess the cost involved in health care services with 60 persons divided into Physical (spinal cord injury) and intellectual disability. In-depth interviews and Focus Group Discussions (FGDs) were conducted for qualitative study to find out their experiences regarding barriers, coping strategies and their needs and expectation when accessing health care services.
\end{abstract}

Physical (spinal cord injury) disability accounted $46.67 \%$ while $53.33 \%$ were intellectual disabled. $48.3 \%$ were in poor health and $51.67 \%$ in fair health condition. The total mean values of direct medical cost for both types of disability were Rs. 6682.53 in the past six month. The qualitative reports suggest that people with severe disability faces numbers of barriers in accessing health services. This is seen as the key reason for their poor heal th outcome. High cost incurred in medical services and physical health maintenance, worse socio-economic status, and layers of barriers in accessing health care services were the reason of poorer heal th outcome and exclusion from the society.

Key words: Physically disabled, spinal cord injury, intellectual disability, direct survey approach, direct medical cost, direct non-medical cost, indirect cost.

\section{INTRODUCTION}

There are many barriers that keep people with disabilities from fully engaging in health care services (Story et. al., 2009). Access can be seen as a right to have or gain entry and/or the opportunity to avail of something (Sowney \& Barr, 2004). Bommier and Stecklov (2001) propose that access to health resources is a basic right and that health access should be distributed equally in an ideal society. The World Report on 
Disability notes that disability is associated with a diverse range of primary health conditions which may result in poor health and high health care needs. Furthermore, there is reciprocal relationship between ill-health, poverty and vulnerability. Disability imposes physical, economic, and psycho-social burden on individuals, their families and society (WHO, 2011). People with disabilities were also more likely to delay health care due to cost than people without disabilities (Chevarley et al., 2006).

In considering the extent and impact of disability it is important to understand the association between disability and health care cost as well as access to health services. Internationally, economic studies have contributed substantially to the understanding of many disability issues. However, no economic studies have been found in Nepal which assesses the cost associated with health care services of severely disabled people. Although there is a lack of exact data of severely disabled people, study should be carried out to design the policy to address the need of health care arising after disability according to their severity. Also, enhancing disabled people's ability to access quality health care at low cost or free of cost may support to meet the objectives outlined in Millennium Development Goals and poverty alleviating effort of government. Interventions to promote the wellbeing and social inclusion include policies to ensure adequate income and assistance for people living with chronic disability or for their caregiver and family. We believe that addressing the cost items involved in receiving health care services and physical health maintenance of disability incurred by disabled individuals can have a substantial impact on standard of living and social inclusion.

Research has identified the factors that contribute to an individual's ability to access health care services. Pechansky and Thomas (1981) define access as a concept representing the degree of "fit" between the clients and the system. In adapting this dimension of access, Simeonsson et al. (1999) identified five characteristics of access to health care: Availability - the type and extent of services, Accessibility - physical barriers relative to location, Accommodation - sensitivity to individual differences or functioning, Affordability - financial, time or energy costs, and Acceptability - mutual acceptance and reciprocity.

The Three-Year Interim Plan (2007-2010) has laid stress on the realization of universal free essential health service in line with the MDGs. Also the government of Nepal ratified the United Nations Convention on the Rights of Persons with Disabilities(UNCRPD) in 2010 which in its articles 9 and 25 talked about accessibility in transportation, public places and equitable health services. Similarly, the government of Nepal has provided certain health care services since 2006 including essential drugs to reduce the out of pocket expenditure from the patients (RECPHEC, 2010). World Report on Disability 2011 suggests that people with disabilities have more health care needs. Hence, in order to improve access to affordable health services for people with disabilities, specific health financing strategies are essential (WHO, 2011). 
Our work may contribute to the literature in a number of ways. Firstly, we have estimated direct medical costs, direct non-medical cost and indirect cost of severely disabled people in Nepal. Secondly, this study carried out the differences in costs between the physically (spinal cord injury) and intellectually disabled. In addition, we have tried to identify the barriers faced by severely disabled people in accessing health care services. Lastly, this research study will contribute to the literature by identifying the strategies adopted by the disabled in the face of the barriers encountered, their needs and expectations. The main objective of this paper is to estimate direct medical, non-medical cost, indirect costs and compare the cost of physical and intellectual disability.

\section{METHODOLOGY}

The study was conducted in Chitwan district, Nepal.We considered only two types of severely disabled people 'physically disabled' (spinal cord injury) and 'intellectually disabled' as the respondents for the study. Convenience sampling method was employed. Sixty respondents were chosen through snow ball sampling with equal proportion from both types of disabilities keeping in mind to include male and female equally. 32 intellectually disabled and 28 physically disabled people were eventually selected for the survey.

For primary data, both quantitative and qualitative approaches were employed to carry out the research. For the quantitative study, Direct Survey Approach (DSA) was employed to estimate the economic cost of severely disabled people, also known as the subjective approach, involves asking individuals with severe disability (or their care taker) how much total cost they had spent on direct medical and non-medical goods and services. The DSA is in practice the most straightforward approach as any costs item identified can be aggregated to give an estimate of total costs arising from a health complication. Furthermore, it is relatively straightforward and inexpensive to implement (Berthoud et al., 1993).

For the qualitative study, Focus Group Discussion, Key Informant Interview and Observation were applied to finding the accessibility of health services. A checklist was designed for the focus group discussion. The first round of focus group discussions were held with medical persons, disabled people and their care taker to finalize the direct medical and non-medical cost items.

\section{Variables Included in the Study}

The questionnaire included demographic and socio economic characteristics, general health information, expenditure on capital items, expenditure on regular items, maintenance cost, transportation cost incurred in different services, time spent by the care taker when receiving health care services and regular time spent at home, 
and benefit and allowances were included. Direct medical cost was sub categorized into last visit and visit in the past six months. Similarly, direct non-medical cost was divided into capital expenditure and recurrent expenditure. And, indirect cost was divided into time care cost at hospital and at home, and transportation cost when receiving health services.

Costs were calculated summarizing all the cost items. Annual equivalent costs were calculated using annuity factor at 3\% and 5\% discount rate to calculate capital expenditure. To calculate the time care cost, all the time were converted into hour and multiplied by hourly cost Rs. 39.75 (8000 monthly) specified by Ministry of Labour, Government of Nepal.

\section{Data Analysis and Interpretation}

All the quantitative data gathered from field survey were transformed in CSPRO software package and then transferred into STATA software. Regression analysis was carried out to estimate the direct medical cost, direct non-medical cost, and the indirect cost. Also, t-test was carried out for the comparison of difference of costs between physical (spinal cord injury) and intellectual disability.

\section{RESULTS}

The mean age of the respondents was found to be 29.28. Majority of them were married (71.19\%), percentage of Brahmin/Kshetri was higher (65\%) than that of indigenous groups of people called Adibasi/Janajati (23.33\%), and few were Dalits, who were traditionally considered untouchables (11.67\%). More than half of them $(53.33 \%)$ were disabled since birth, some sustained disability due to accident (31.67\%) whereas a few of their disability was due to diseases (11.67\%). Only 45 percent of the respondents were literate, mean years of education was 7.70 years.

A large proportion of them were unemployed before they became disabled (68.33\%). The mean salary they used to earn before disability was Rs. 8897.36. It was also found that almost all of them $(96.67 \%)$ were unemployed after disability. Almost three quarter $71.67 \%$ (43) of the household were engaged in agriculture, $13.33 \%$, engaged in business, $4.84 \%$ engaged in services, $3.33 \%$ has been getting pension $\%$, and remaining have other sources of income. It was also noted that $91.67 \%$ have been receiving the government allowances provided to the disabled people and the remaining $8.33 \%$ had not received the allowances yet. It was also found that $48.33 \%$ had poor health condition whereas remaining $51.67 \%$ had fair health, and all of them needed a care taker for their daily life. 
The different cost categories associated with disability are summarised in Table 1 and two sample t-test with equal variance is summarised in Table 2.The following paragraphs contain the analysis of the different cost components.

\section{Direct Medical Cost Associated to Health Care Services}

\section{Direct Medical Cost in the Last Six Months}

People with physical disability and intellectual disability spent on average Rs. 9931.071 and Rs. 3840.063 respectively in the last six month, the mean expenditure being Rs. 6682.53. The difference was found significant only at $10 \%$ level of significance $(\mathrm{p}=0.088)$.

\section{Direct Medical Cost in the Last Visit}

The average cost of last visit to hospital as an inpatient for both types of disability was Rs. 167563.4. As inpatient, physically disabled and intellectually disabled spent on average Rs. 259120.4 and Rs. 87451.13 respectively. The difference was statistically significant even at $1 \%$ level of significance ( $\mathrm{p} 0.0038$ ).

\section{Direct Non-medical Cost Associated to Physical Health Maintenance}

\section{Capital Expenditure}

The mean values of capital expenditure for both types of disabilities at 5\% and 3\% discount rates were Rs. 3969.76 and Rs. 3752.11 respectively. The difference in the mean values of annual equivalent cost of capital expenditure for people with physical disability and intellectual disability at 5\% discount rate were Rs. 6037.178 and Rs. 2160.774 respectively, which are statistically highly significant $(p=0.002)$; similarly, the difference at $3 \%$ discount rate was found statistically highly significant $(\mathrm{p}=0.0003)$.

\section{Monthly Recurrent Expenditure}

The mean value of monthly recurrent expenditure for both types of disability was Rs. 322.14. Its difference in the mean values for people with physical disability (Rs. 387.89) and for people with intellectual disability (Rs. 183.33) was found to be highly significant $(\mathrm{p}=0.001)$.

\section{Indirect Cost}

\section{Time Cost when Receiving Health Care Services}

The mean value of time cost in receiving medical services (last visit as inpatient + last six month visit) for both types of disability was Rs. 41,853.44. Its value for physically 
disabled) was Rs. 57726.94 and for intellectually disabled was Rs. 27964.13. The difference was found to be statistically insignificant $(p=0.1184)$.

Table 1: Direct and Indirect Cost Associated with Disability

\begin{tabular}{|c|c|c|c|c|c|c|c|c|}
\hline \multirow[b]{2}{*}{ Variables } & \multicolumn{2}{|c|}{ Direct medical cost } & \multicolumn{3}{|c|}{ Direct non-medical cost } & \multicolumn{3}{|c|}{ Indirect cost } \\
\hline & $\begin{array}{c}\text { Six } \\
\text { month }^{1}\end{array}$ & $\begin{array}{c}\text { Last } \\
\text { visit }^{2}\end{array}$ & $\begin{array}{c}\text { Capital } \\
\text { cost in } \\
5 \%^{3}\end{array}$ & $\begin{array}{c}\text { Capital } \\
\text { cost in } \\
3 \%\end{array}$ & $\begin{array}{l}\text { Monthly } \\
\text { recurrent } \\
\text { exp. }\end{array}$ & $\begin{array}{l}\text { Total } \\
\text { time } \\
\text { cost }^{4}\end{array}$ & $\begin{array}{c}\text { Total } \\
\text { trans. } \\
\text { Cost }^{5}\end{array}$ & $\begin{array}{l}\text { Time cost } \\
\text { monthly }\end{array}$ \\
\hline Physical & 28 & 28 & 28 & 28 & 19 & 28 & 28 & 26 \\
\hline Mean & 9931.07 & 259120.4 & 6037.17 & 5676.87 & 387.89 & 57726.94 & 5825.71 & 7274.25 \\
\hline Std. & 18583.59 & 300228.2 & 5340.10 & 5094.68 & 217.42 & 70844.66 & 6380.86 & 4340.51 \\
\hline Min & 0 & 0 & 1382.55 & 1284.04 & 80 & 119.25 & 0 & 1033.5 \\
\hline $\operatorname{Max}$ & 89360 & 1415834 & 28073.5 & 26885.11 & 1000 & 373650 & 25100 & 12402 \\
\hline Intellectual & 32 & 32 & 32 & 32 & 9 & 32 & 32 & 32 \\
\hline Mean & 3840.06 & 87451.13 & 2160.77 & 2067.95 & 183.33 & 27964.13 & 4000 & 7622.06 \\
\hline Std. & 6740.23 & 108952.8 & 1305.79 & 1237.94 & 66.143 & 74012.61 & 3808.25 & 3509.68 \\
\hline Min & 0 & 1000 & 0 & 0 & 100 & 238.5 & 120 & 3100.5 \\
\hline Max & 25410 & 550000 & 5614.72 & 5293.77 & 300 & 429300 & 15000 & 12402 \\
\hline Total & 60 & 60 & 60 & 60 & 28 & 60 & 60 & 58 \\
\hline Mean & 6682.53 & 167563.4 & 3969.76 & 3752.118 & 322.14 & 41853.44 & 4852 & 7466.14 \\
\hline Std. & 13831.2 & 234404.4 & 4212.98 & 3997.48 & 205.61 & 73479.42 & 5205.40 & 3872.05 \\
\hline Min & 0 & 0 & 0 & 0 & 80 & 119.25 & 0 & 1033.5 \\
\hline Max & 89360 & 1415834 & 28073.5 & 26885.11 & 1000 & 429300 & 25100 & 12402 \\
\hline
\end{tabular}

Source: Author's estimation

\section{Monthly Time Cost at Home}

The mean value of monthly time cost at home for both types of disability was Rs. 7466.14. It was Rs. 7274.25 and Rs. 7622.06 for physically disabled and intellectually disabled people respectively., and the difference was statistically not significant $\mathrm{p}=$ 0.737).

\section{Transportation Cost}

The mean value of transportation cost for both types of disability was Rs. 4852. Its value for people with physical disability was Rs. 5825.71 and Rs. 4000 for people with intellectual disability. The difference is statistically insignificant $(p=0.177)$. 
Table 2: Two Sample t-test with Equal Variance

\begin{tabular}{|c|c|c|c|c|c|c|}
\hline Group & Obs. & Mean & Std. Err. & \multicolumn{2}{|c|}{ [95\% Conf. Interval] } & t-stat(p-value) \\
\hline \multicolumn{7}{|c|}{ Total time cost given when medical service received } \\
\hline Physical(spinal) & 28 & 57726.94 & 13388.38 & 30256.25 & 85197.63 & \multirow[t]{3}{*}{$1.59(0.118)$} \\
\hline Intellectual & 32 & 27964.13 & 13083.71 & 1279.73 & 54648.52 & \\
\hline Difference & & 29762.81 & 18775.41 & -7820.26 & 67345.88 & \\
\hline \multicolumn{7}{|c|}{ Capital expenditure annual equivalent cost at $5 \%$ disc. } \\
\hline Physical(spinal) & 28 & 6037.18 & 1009.19 & 3966.5 & 8107.86 & \multirow[t]{3}{*}{$3.98(0.002)$} \\
\hline Intellectual & 32 & 2160.77 & 230.83 & 1689.98 & 2631.56 & \\
\hline Difference & & 3876.41 & 974.67 & 1925.39 & 5827.42 & \\
\hline \multicolumn{7}{|c|}{ Capital expenditure annual equivalent cost at $3 \%$ disc. } \\
\hline Physical(spinal) & 28 & 5676.88 & 962.81 & 3701.36 & 7652.39 & \multirow{3}{*}{$3.88(<0.001)$} \\
\hline Intellectual & 32 & 2067.96 & 218.84 & 1621.63 & 2514.28 & \\
\hline Difference & & 3608.92 & 929.5 & 1748.32 & 5469.52 & \\
\hline \multicolumn{7}{|c|}{ Total transportation cost } \\
\hline Physical(spinal) & 28 & 5825.71 & 1205.87 & 3351.47 & 8299.95 & \multirow[t]{3}{*}{$1.37(0.177)$} \\
\hline Intellectual & 32 & 4000 & 673.21 & 2626.98 & 5373.02 & \\
\hline $\begin{array}{l}\text { Difference } \\
\text { Medical cost in la }\end{array}$ & onth & 1825.71 & 1337.27 & -851.13 & 4502.56 & \\
\hline Physical(spinal) & 28 & 9931.07 & 3511.97 & 2725.11 & 17137.03 & \multirow[t]{3}{*}{$1.73(0.089)$} \\
\hline Intellectual & 32 & 3840.06 & 1191.52 & 1409.95 & 6270.18 & \\
\hline Difference & & 6091.01 & 3520.17 & -955.38 & 13137.4 & \\
\hline \multicolumn{7}{|c|}{ Cost of last visit to hospital } \\
\hline Physical(spinal) & 28 & 259120 & 56738 & 142704 & 375537 & \multirow[t]{3}{*}{$3.02(0.004)$} \\
\hline Intellectual & 32 & 87451 & 19260 & 48169 & 126733 & \\
\hline Difference & & 171669 & 56875 & 57823 & 285516 & \\
\hline \multicolumn{7}{|c|}{ Monthly recurrent expenditure } \\
\hline Physical(spinal) & 19 & 387.895 & 49.88 & 283.1 & 492.69 & \multirow{3}{*}{$2.74(0.01)$} \\
\hline Intellectual & 9 & 183.333 & 22.048 & 132.491 & 234.176 & \\
\hline Difference & & 204.561 & 74.695 & 51.024 & 358.099 & \\
\hline \multicolumn{7}{|c|}{ Regular time cost in a month } \\
\hline Physical(spinal) & 26 & 7274.3 & 851.2 & 5521.1 & 9027.4 & \multirow{3}{*}{$-0.34(0.737)$} \\
\hline Intellectual & 32 & 7622.1 & 620.4 & 6356.7 & 8887.4 & \\
\hline Difference & & -347.8 & 1030.4 & -2411.9 & 1716.3 & \\
\hline
\end{tabular}

Source: Author's estimation 


\section{DISCUSSION}

The mean values of direct cost on medical services in the past six months and last visit were Rs. 6682.53 and Rs. 167563.4 respectively. The value of direct medical cost was Rs. 9931.07 for physical disability and Rs. 3840 for intellectual disability in the past six months; and the values were Rs. 259120.4 and Rs. 87451.13 respectively in the last visit as inpatient. Access Economics in 2008 in Australia found that health care cost for paraplegia (paralysis of lower half body) was $\$ 52.5$ million and $\$ 76.5$ million for quadriplegic (paralysis of both arms and legs) in Australia. Similarly, the estimated health care cost was $\$ 13.5$ million for paraplegia and \$24.7 million for quadriplegic in Victoria in 2008 price (Economics, 2009). LSE research online article conducted a research in 2005 on 930 intellectually disabled people and found that the weekly cost for acute health care was 7 pound sterling, 75 pound sterling for day care and 22 pound sterling for community services (Knapp, et. al.2005). Another research conducted in Tanzania in 2013 estimated that the mean value of expenditure on health cares as an inpatient was 49 dollars and 6 dollars for outpatient for 3 months and the study only measured the direct medical cost (Stoermer et al., 2013).

The result of the study showed that the total mean value of yearly cost on capital items at 5\% and 3\% discount rates were Rs. 3969.76 and Rs. 3752.1 respectively. Similarly, the total mean value of monthly recurrent expenditure was Rs. 322.1. Access Economics Australia estimated that the expenditure on aids and modification cost were 113.2 and 113.6 million dollars for paraplegia and quadriplegic respectively. Similarly, in Victoria, the cost were 30.4 and 36.5 million dollars for paraplegia and quadriplegic (Economics, 2009). The results from Access Economics, Australia pertain to the national level and they cover only paraplegics and quadriplegics; however, our study represents unit cost of severe disabilities.

Whatsoever the unit of analysis, the economic burden needs to be addressed by the concerned agencies such as the government according to the level of severity. Increment in monthly allowances according to the level of severity and providing necessary equipment may help reduce the burden.

The mean value of time cost in receiving medical services was Rs. 41853.4. Similarly, the mean value of monthly regular time cost at home was Rs. 7466.1. The mean value for physical and intellectual disabilities were Rs. 57726.94 and Rs. 27964.13 respectively. Similarly, the result shows that the regular time cost at home for intellectual disability was Rs. 7622 which was slightly more than that for physical disability (Rs 7274). The average time given at home by the family members was 7.22 hours. 
The research conducted in Australia in 2009 reported that the long term care was 109 million dollars for paraplegia and 500.7 dollars for quadriplegic in Australia. However, in Victoria, the long term care cost was 29.3 million dollars for paraplegia and 155.1 million dollars for quadriplegic. The average number of hours spent by care taker for spinal cord injury was 40 hours per week in Queensland, Australia (Rowell \& Connelly, 2008). On average, formal care givers provided 12 hours of care per day in USA (Robinson et al. 2009, cited in Access Economics, 2009). Similarly, the total mean value of transportation cost in receiving medical services both in last visit and in past six months was Rs. 4852 for both types of disability. As seen from our study, the physically disabled people and intellectually disabled people spent an average Rs. 5825.71 and Rs. 4000 respectively. The study conducted by GIZ in Tanzania in 2013 found that $67 \%$ of the respondents reported to have incurred on an average 25 US\$ as transport costs.

It seems from the study within or outside the country that the people with severe disability require full time assistance for their regular care. The result shows that physical disability incurred more cost on all items categorized above. The physical, emotional, and social consequences from a spinal cord injury can be devastating resulting from loss of sensation and motor function. Bed sores or pressure sores, urine infection, respiratory problem are common with SCI injury patients who tend to lie in a single position for a long time. It happens mainly in patients who have loss of sensation because of spinal cord injury. However, the result shows that the intellectual disability requires more time cost as a regular care. Intellectual disabled people cannot express their desire and emotion. Some of the intellectually disabled people like those with Autism need care all the time.

\section{CONCLUSION}

The findings of the report suggest that persons with disabilities experience worse socio-economic outcomes and are more prone to poverty. Since people with disabilities have high rate of cost involved in receiving medical services and physical health maintenance, have lower educational achievements, and are less involved in different activities, they seem to be at higher risk of poorer health outcomes. The costs of health significantly vary by severity and types of disability. These findings are important for considering the effectiveness of policies that aim to address the economic and several other problems associated with severe disability.

\section{Acknowledgements}

I am thankful to UNICEF and Institute for Nepal Environment and Health System Development (INEHD) for financial supports, Dr. Shiva Raj Adhikari for supervising 
this work, Mr. Vishnu Sapkota for his valuable inputs and guidance, Sourab Mohan Joshi, Krishna Dhakal, Babu Ram Regmi, Bashudev, Milan Kharel, Sanjib Adhikari, Sandesh Katuwal and Mr. Jiwan Nath Dhungana for their helps in carrying out this work. Last but not the least, I am indebted to all the respondents for their overwhelming participation in the survey.

\section{References}

Access Economics. (2009). The economic cost of spinal cord injury and traumatic brain injury in Australia. Report by Access Economics for the Victorian Neurotrauma Initiative. Canberra: Access Economics, 31.Retrieved from https:/www.tac.vic. gov.au/about-the-tac/our-organisation/research/tac-neurotrauma-research/ vni/the20economic20 cost20of20spinal20cord20injury20and20traumatic 20brain20injury 20in20australia.pdf

Berthoud, R., Lakey, J., \& McKay, S. (1993). The economic problems of disabled people. London: Policy Studies Institute.

Bommier, A., \& Stecklov, G. (2001). Defining health inequality: Why Rawls succeeds where social welfare theory fails. Journal of Health Economics, 21,497-513. Available at: www.breastcheck.ie

Chevarley, F.M., Thierry, J.M., Gill, C.J., Ryerson, A.B., \& Nosek, M.A. (2006). Health, preventive health care, and health care access among women with disabilities in the 1994-1995 national health interview survey, supplement on disability. Women's Health Issues, 16, 297-312.

Stoermer, M., Kessy, F., \& Widmer, T. (2013). Inclusion of the poor and vulnerable into the new health financing strategy: Final report.Knapp, M.

Comas-Herrera, A., Astin, J., Beecham, J., Pendaries, C. (2005). Intellectual disability, challenging behaviour and cost in care accommodation: what are the links? London: LSE Research Articles Online. Available at: http://eprints.lse.ac.uk/ archive/00000336/

Pechansky, R., \& Thomas, C. (1981). The concept of access: Definition and relation to customer satisfaction. Medical Care, 19 (2), 127-140.

RECPHEC (2010). Briefing paper on essential health care services in Nepal. Retrieved from http://www.ridanepal.org/downloaded/EHCS\%20briefing\%20paper.pdf

Rowell, D., \& Connelly, L.B. (2008). Personal assistance, income and employment: the spinal injuries survey instrument (SISI) and its application in a sample of people with quadriplegia' Spinal Cord, 46,417-424. Cited by: Access economics (2009). The economic cost of SCI and traumatic brain injury. Australia 
Simeonsson, R.J., Bailey, D.B., Scandlin, D., Huntington, G.S., \& Roth, M. (1999). Disability, health, secondary conditions and quality of life: Emerging issues in public health. In R.J. Simeonsson \& L.N. McDevitt (Eds.), Issues in disability and health: The role of secondary conditions and quality of life (pp.51-72). Chapel Hill: University of North Carolina Press.

Sowney, M., \& Barr, O. (2004). Equity of access to health care for people with learning disabilities: A concept analysis. Journal of Learning Disabilities, 8(3), 247-265.

Story, M. F., Schwier, E., \& Kailes, J.I. (2009). Perspectives of patients with disabilities on the accessibility of medical equipment: Examination tables, imaging equipment, medical chairs, and weight scales. Disability and Health Journal, 2(4), 169-179.e1

WHO (2011). World report on disability 2011. World Health Organization. Accessed at www.who.org 